\title{
Effect of a single tetanus-diphtheria vaccine dose on the immunity of elderly people in São Paulo, Brazil
}

\section{L.Y. Weckx ${ }^{1}$, K. Divino-Goes ${ }^{1}$, D.M. Lihama ${ }^{1}$, E. Carraro², N. Bellei ${ }^{2}$, C.F.H. Granato ${ }^{2}$ and M.I. de Moraes-Pinto ${ }^{1}$}

\author{
${ }^{1}$ Disciplina de Infectologia Pediátrica, ${ }^{2}$ Disciplina de Infectologia, \\ Escola Paulista de Medicina, Universidade Federal de São Paulo, \\ São Paulo, SP, Brasil
}

\section{Correspondence \\ M.I. de Moraes-Pinto \\ Rua Pedro de Toledo, 781, 9o andar \\ 04039-032 São Paulo, SP \\ Brasil \\ Fax: +55-11-5575-6928 \\ E-mail: m.isabelmp@uol.com.br}

Publication supported by FAPESP.

$\ldots \ldots \ldots \ldots \ldots \ldots$

Received May 31, 2005

Accepted February 14, 2006

\begin{abstract}
Epidemiological data regarding tetanus and diphtheria immunity in elderly people in Brazil are scarce. During the First National Immunization Campaign for the Elderly in Brazil in April 1999, 98 individuals (median age: 84 years) received one tetanus-dyphtheria (Td) vaccine dose (Butantan Institute, lot number 9808079/G). Inclusion criteria were elderly individuals without a history of severe immunosuppressive disease, acute infectious disease or use of immunomodulators. Blood samples were collected immediately before the vaccine and 30 days later. Serum was separated and stored at $-20^{\circ} \mathrm{C}$ until analysis. Tetanus and diphtheria antibodies were measured by the double-antigen ELISA test. Tetanus and diphtheria antibody concentrations lower than $0.01 \mathrm{IU} / \mathrm{mL}$ were considered to indicate the absence of protection, between 0.01 and $0.09 \mathrm{IU} / \mathrm{mL}$ were considered to indicate basic immunity, and values of $0.1 \mathrm{IU} / \mathrm{mL}$ or higher were considered to indicate full protection. Before vaccination, $18 \%$ of the individuals were susceptible to diphtheria and $94 \%$ were susceptible to tetanus. After one Td dose, $78 \%$ became fully immune to diphtheria, $13 \%$ attained basic immunity, and $9 \%$ were still susceptible to the disease. In contrast, $79 \%$ remained susceptible to tetanus, $4 \%$ had basic immunity and $17 \%$ were fully immune. Although one Td dose increases immunity to diphtheria in many elderly people who live in Brazil, a complete vaccination series appears to be necessary for the prevention of tetanus.
\end{abstract}

\section{Introduction}

The impact of routine childhood immunization on the epidemiology of many diseases is well known. A clear example is the dramatic decline in the incidence of diphtheria in industrialized countries (1). In parallel, many of these countries have realized that
Key words

- Elderly

- Tetanus

- Immunization
- Diphtheria 
toxoid are needed to maintain immunity in the adult population (3).

However, acquisition of immunity against other diseases has not changed with time: protection against tetanus, for instance, can only be achieved through vaccination of each individual and subsequent boosters are needed in order to maintain protective antibody levels (4).

Vaccination of the elderly population has now been recommended as a routine in some countries (5). Assessing immunity to vaccine-preventable diseases in the elderly is necessary in order to provide a correct immunization scheme.

In Brazil, the First National Influenza, Pneumococcus, Tetanus and Diphtheria Vaccination Campaign for the Elderly took place in 1999 (6). In order to identify immunity before the introduction of that program and the effect of the administration of one dose of tetanus and diphtheria vaccine (Td) on that population, we tested tetanus and diphtheria antibodies in 98 individuals pre- and post-vaccination.

\section{Material and Methods}

The study was conducted at a Nursing Home in São Paulo, SP, Brazil, during the First National Immunization Campaign for the Elderly in April 1999. Written informed consent was obtained from participants and/ or their legal guardians before enrollment in the study.

Inclusion criteria were elderly individuals without a history of severe immunosuppressive disease, acute infectious disease or use of immunomodulators. Ninety-eight of the 120 patients who participated in the major study were selected because serum samples were available before and after the administration of a Td dose. The median age of the 98 participants was 84 years (range: 68 to 99$) ; 23.5 \%$ were men and $76.5 \%$ women. Most were individuals originally from Eastern Europe who had immigrated to
Brazil in the last 60 years and had been living in a nursing home for more than 8 years. Only $12.3 \%$ of them reported previous tetanus vaccination and no data were available for diphtheria vaccination.

All individuals received one dose $(0.5$ $\mathrm{mL}$ ) of Td vaccine (Butantan Institute, São Paulo, SP, Brazil) containing 10 Lf (Limes flocculation unit) per dose of tetanus toxoid and $2 \mathrm{Lf}$ per dose of diphtheria toxoid adsorbed onto aluminum toxoid and with thimerosal as a preservative. Blood samples were collected from all participants immediately before vaccination and 30 days after the procedure. Serum was separated and stored at $-20^{\circ} \mathrm{C}$ until analysis. Antibodies against tetanus and diphtheria were measured by the double-antigen ELISA test, as previously described (7).

Tetanus toxoid (Butantan Institute) diluted in $0.1 \mathrm{M}$ carbonate-bicarbonate buffer, pH 9.6, was used to coat 96-well microtiter plates (Thermolab System, Chantilly, VA, USA) overnight at $4^{\circ} \mathrm{C}$. Two-fold serial dilutions of serum samples and of tetanus reference serum (in-house standard calibrated against "Tetanus antitoxin human immunoglobulin NIBSC reagent 1976 (76/589)") in dilution buffer (10 mM PBS, pH 7.2, $1 \%$ Triton X-100) with $1 \%$ bovine serum albumin were added to the plate and incubated for $1 \mathrm{~h}$ at $37^{\circ} \mathrm{C}$. Biotin-labeled tetanus toxoid in dilution buffer was then added to the plate and incubated for $1 \mathrm{~h}$ at $37^{\circ} \mathrm{C}$. Streptavidinalkaline phosphatase conjugate (Zymed, San Francisco, CA, USA) in dilution buffer was incubated for $1 \mathrm{~h}$ at $37^{\circ} \mathrm{C}$. $p$-Nitrophenylphosphate (Sigma, St. Louis, MO, USA) in 1 $\mathrm{M}$ diethanolamine, $5 \mathrm{mM}$ magnesium chloride buffer, $\mathrm{pH}$ 9.8, was used as substrate and absorbance at $450 \mathrm{~nm}$ was read with an immunoreader ELX-800 (Bio-Tek Instruments, Winooski, VT, USA). Between steps, the plate was washed five times in dilution buffer.

The same method was used for diphtheria antibodies, with some modifications: diph- 
theria toxoid (Butantan Institute), diphtheria reference serum (in-house standard calibrated against "Diphtheria antitoxin human serum 91/534" - NIBSC reagent) and biotin-labeled diphtheria toxoid were used.

Tetanus and diphtheria antibodies are reported as IU/mL using the curve comparison method to transform optical density to concentration units.

Patients were classified according to internationally accepted criteria of protective antibody levels (8-12). Tetanus and diphtheria antibody concentrations lower than 0.01 $\mathrm{IU} / \mathrm{mL}$ were considered to indicate the absence of protection, between 0.01 and 0.09 $\mathrm{IU} / \mathrm{mL}$ were considered to indicate basic immunity, and values of $0.1 \mathrm{IU} / \mathrm{mL}$ or higher were considered to indicate full protection.

Due to the non-normal distribution of the data, values were log-transformed before comparison between pre- and post-booster mean antibody concentrations by the paired $t$-test. The chi-square test was used to evaluate a possible association between booster and categories of immunity to tetanus and diphtheria.

\section{Results}

\section{Categories of immunity to tetanus and diphtheria based on pre- and post-vaccination antibodies}

Before one Td vaccine dose, the majority of the individuals analyzed had some degree of immunity against diphtheria (absence of immunity: $18 \%$; basic immunity: $37 \%$; full immunity: $45 \%$ ). By contrast, $94 \%$ of them were susceptible to tetanus and the remaining $6 \%$ had only basic immunity.

After vaccination, $78 \%$ of the subjects were fully immune to diphtheria, $13 \%$ had basic immunity and $9 \%$ remained susceptible. For tetanus, the post-vaccination proportions were: $17 \%$ fully immune, $4 \%$ with basic immunity and $79 \%$ still without protection. For both diseases, the proportions of individuals in each category of immunity were significantly different pre- and postvaccination, with an increase in the percentage of immune subjects $(\mathrm{P}<0.001$ for diphtheria and tetanus, chi-square test; Table 1).

\section{Diphtheria antibodies pre- and post-vaccination}

As observed when categories of immunity were analyzed, geometric mean antibody values increased with one Td dose (diphtheria: pre-Td, 0.072 and post-Td, $1.456 \mathrm{IU} /$ $\mathrm{mL}, t$-test, $\mathrm{P}<0.001$; tetanus: pre-Td, 0.005 and post-Td, $0.014 \mathrm{IU} / \mathrm{mL}, t$-test, $\mathrm{P}<0.001$ ). Of note, diphtheria geometric mean antibody concentrations were statistically higher than tetanus values before and after vaccination $(\mathrm{P}<0.001$ for both comparisons, $t$-test; Figure 1).

Interestingly, women responded better than men to the booster dose: while diphtheria geometric mean antibodies increased significantly for men (pre-Td, 0.060 and post$\mathrm{Td}, 0.897 \mathrm{IU} / \mathrm{mL}, \mathrm{P}<0.001, t$-test $)$ and women (pre-Td, 0.077 and post-Td, 1.689 $\mathrm{IU} / \mathrm{mL}, \mathrm{P}<0.001, t$-test), only women had an increase in tetanus geometric mean antibodies (women: pre-Td, 0.005 and post-Td, $0.017 \mathrm{IU} / \mathrm{mL}, \mathrm{P}<0.001$, $t$-test; men: pre-Td, 0.005 and post-Td, $0.007 \mathrm{IU} / \mathrm{mL}, \mathrm{P}=0.187$, $t$-test).

\begin{tabular}{l}
$\begin{array}{l}\text { Table } 1 . \text { Effect of a single tetanus-diphtheria vaccination on the categories of immunity } \\
\text { to both diseases in elderly subjects at the time of vaccination and } 30 \text { days later. }\end{array}$ \\
\begin{tabular}{lcc} 
& Pre-vaccination & Post-vaccination \\
\hline & & \\
Diphtheria* & $18(18 \%)$ & $9(9 \%)$ \\
Absence of immunity $(<0.01 \mathrm{IU} / \mathrm{mL})$ & $36(37 \%)$ & $13(13 \%)$ \\
Basic immunity $(\geq 0.01 \mathrm{and}<0.1 \mathrm{IU} / \mathrm{mL})$ & $44(45 \%)$ & $76(78 \%)$ \\
Full immunity $(\geq 0.1 \mathrm{IU} / \mathrm{mL})$ & & \\
Tetanus* & $92(94 \%)$ & $77(79 \%)$ \\
Absence of immunity $(<0.01 \mathrm{IU} / \mathrm{mL})$ & $6(6 \%)$ & $4(4 \%)$ \\
Basic immunity $(\geq 0.01 \mathrm{and}<0.1 \mathrm{IU} / \mathrm{mL})$ & $0(0 \%)$ & $17(17 \%)$ \\
Full immunity $(\geq 0.1 \mathrm{IU} / \mathrm{mL})$ &
\end{tabular} \\
\hline
\end{tabular}

Data are reported as number and percent. ${ }^{*} P<0.001$, categories of pre-vaccination compared to post-vaccination for both diphtheria and tetanus (chi-square test). 


\section{Discussion}

We observed that, although the majority of individuals in our study group were fully protected against diphtheria, only $6 \%$ of them had basic immunity to tetanus and none had tetanus antibodies that would confer full protection. After one Td dose, a shift to higher categories of immunity was observed for both tetanus and diphtheria. However, the contrast between protection against the two diseases was maintained, with the vast majority of the individuals still being susceptible to tetanus and now fully immune to diphtheria.

Our tetanus results agree with data reported by other groups in different countries (4). Our epidemiologic situation regarding diphtheria is probably situated between that of industrialized and non-industrialized countries $(8,9)$. There was a high percentage of individuals with pre-vaccination immunity to diphtheria who, analyzed together, displayed low geometric mean antibody concentrations $(0.072 \mathrm{IU} / \mathrm{mL})$. This suggests

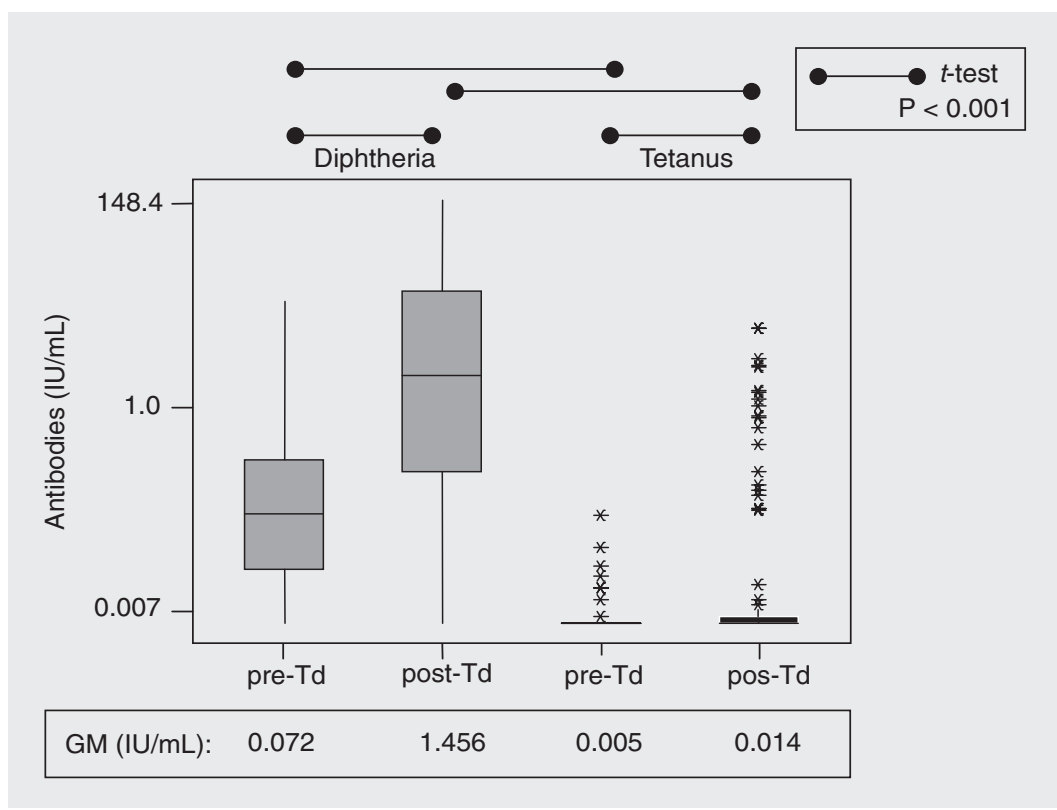

Figure 1. Tetanus and diphtheria antibodies pre- and post-one tetanus-diphtheria (Td) vaccination. Horizontal lines in boxplots indicate the 25th, 50th, and 75th percentiles. Outlying values (present only for tetanus) are depicted as asterisks. Geometric means (GM) are shown at the bottom of the figure. previous $C$. diphtheriae infection with rare subsequent exposures to the bacillus (2). Indeed, diphtheria has been decreasing in Brazil over the last decades, with an incidence of 0.01 to 0.04 cases per 100,000 inhabitants in the State of São Paulo during the last few years (13).

For this reason, one Td dose had an effect suggestive of a diphtheria booster on the majority of the population. On the other hand, although mean tetanus antibodies increased after one dose, the persistence of so many still susceptible individuals indicates that this was their primary contact with the antigen. Interestingly, when analyzed separately, women showed a better immune response to tetanus (but not to diphtheria) than men.

As also reported by others $(14,15)$, we have shown that elderly individuals can respond to tetanus and diphtheria toxoids. However, even for diphtheria, a single vaccine dose was insufficient to obtain adequate protection for those who had not been previously exposed to the antigen (16).

As is the case for other developing countries, Brazil has a growing elderly population (17) that is now exposed to a different environment with less natural booster stimuli when compared with that of previous decades. This emphasizes the necessity of a complete vaccination series for elderly people without a record of immunization. Unfortunately, as already noticed by others (18), even in developed countries, recommendations for immunization practices as part of health maintenance in this population may not be adhered to adequately in the primary care setting.

As a "catch up" strategy and in parallel to routine vaccination, the aged in Brazil are having their tetanus and diphtheria immunization updated during the National Vaccination Campaign for the Elderly that is held yearly since 1999 and they are subsequently referred to routine health care services to complete the primary series. Studies are underway to assess immunity against tetanus and diphtheria after the first years of this strategy. 


\section{References}

1. Galazka A (2000). The changing epidemiology of diphtheria in the vaccine era. Journal of Infectious Diseases, 181 (Suppl 1): S2-S9.

2. Galazka AM, Robertson SE \& Oblapenko GP (1995). Resurgence of diphtheria. European Journal of Epidemiology, 11: 95-105.

3. Galaska AM \& Robertson SE (1996). Immunisation against diphtheria with special emphasis on immunisation of adults. Vaccine, 14: 845-857.

4. Galazka AM (1993). The immunological basis for immunisation series. Module 3: Tetanus. World Health Organization. WHO/EPI/ GEN/93.13.

5. Centers for Disease Control and Prevention (1995). Assessing adult vaccination status at age 50 years. MMWR Morbidity and Mortality Weekly Report, 44: 561-563.

6. Secretaria de Saúde de Ribeirão Preto (2005). Campanha de Vacinação do Idoso. [http://www.ribeiraopreto.sp.gov.br/ssaude/ principal/painel//16Vacin-Idoso.htm]. Accessed February 2006.

7. Kristiansen M, Aggerbeck H \& Heron I (1997). Improved ELISA for determination of anti-diphtheria and/or anti-tetanus antitoxin antibodies in sera. Acta Pathologica et Microbiologica Scandinavica, 105: 843-853.

8. Ipsen J (1946). Circulating antitoxin at the onset of diphtheria in 425 patients. Journal of Immunology, 54: 325-347.

9. Galazka AM (1993). The immunological basis for immunisation series. Module 2: Diphtheria. World Health Organization. WHO/EPI/ GEN/93.12.

10. Gupta RK, Griffin Jr P, Xu J et al. (1996). Diphtheria antitoxin levels in US blood and plasma donors. Journal of Infectious Diseases, 173: $1493-1497$.
11. Stark K, Schonfeld C, Barg J et al. (1999). Seroprevalence and determinants of diphtheria, tetanus and poliomyelitis antibodies among adults in Berlin, Germany. Vaccine, 17: 844-850.

12. von Hunolstein $\mathrm{C}$, Aggerbeck $\mathrm{H}$, Andrews $\mathrm{N}$ et al. (2000). European sero-epidemiology network: standardisation of the results of diphtheria antitoxin assays. Vaccine, 18: 3287-3296.

13. CVE (2005). Difteria. Casos, coeficiente de incidência (100.000 hab), óbitos e letalidade. Estado de São Paulo, 1970 a 2003. [www.cve. saude.sp.gov.br/htm/resp/difte_ob7002.htm]. Accessed May 2005.

14. Carson PJ, Nichol KL, O'Brien J et al. (2000). Immune function and vaccine responses in healthy advanced elderly patients. Archives of Internal Medicine, 160: 2017-2024.

15. Ruben FL, Nagel J \& Fireman P (1978). Antitoxin responses of the elderly to tetanus-diphtheria (TD) immunisation. American Journal of Epidemiology, 108: 145-149.

16. Vellinga A, Van Damme P, Joossens E et al. (2000). Response to diphtheria booster vaccination in healthy adults: vaccine trial. British Medical Journal, 320: 217.

17. IBGE (2005). Pesquisa nacional por amostra de domicílios: síntese de indicadores 2002/IBGE, Coordenação de Trabalho e Rendimento. 2002. IBGE, Rio de Janeiro, RJ, Brazil. [www.ibge.gov.br/ home/estatistica/populacao/trabalhoerendimento/pnad2002/ sintesepnad2002.pdf]. Accessed May 2005.

18. Alagappan K, Rennie W, Kwiatkowski T et al. (1997). Antibody protection to diphtheria in geriatric patients: need for ED compliance with immunisation guidelines. Annals of Emergency Medicine, 30: 455-458. 